\title{
1 Obtaining granular activated carbon from paper mill sludge - a challenge 2 for application in the removal of pharmaceuticals from wastewater
}

4 Guilaine Jaria ${ }^{1}$, Vânia Calisto ${ }^{1 *}$, Carla Patrícia Silva ${ }^{1}$, María Victoria Gil ${ }^{2}$, Marta Otero ${ }^{3}$, Valdemar

$6 \quad{ }^{1}$ Department of Chemistry \& CESAM, University of Aveiro, Campus de Santiago, 3810-193

Aveiro, Portugal

$8 \quad{ }^{2}$ Instituto Nacional del Carbón, INCAR-CSIC, Calle Francisco Pintado Fe 26, 33011 Oviedo, Spain

$9{ }^{3}$ Department of Environment and Planning \& CESAM, University of Aveiro, Campus de Santiago, 
In this work, a granular activated carbon (GAC) was produced using primary paper

27 mill sludge (PS) as raw material and ammonium lignosulfonate (AL) as binder agent. PS is

28 a residue from the pulp and paper industry and AL is a by-product of the cellulose pulp

29 manufacture and the proposed production scheme contributes for their valorisation together

30 with important savings in GAC precursors. The produced GAC (named PSA-PA) and a

31 commercially available GAC (GACN), used as reference material, were physically and

32 chemically characterized. Then, they were tested in batch experiments for the adsorption of

33 carbamazepine (CBZ), sulfamethoxazole (SMX), and paroxetine (PAR) from ultra-pure

34 water and wastewater. Even though GACN and PSA-PA possess very similar specific

35 surface areas $\left(S_{\mathrm{BET}}\right)$ (629 and $671 \mathrm{~m}^{2} \mathrm{~g}^{-1}$, respectively), PSA-PA displayed lower maximum

36 adsorption capacities $\left(q_{\mathrm{m}}\right)$ than GACN for the pharmaceuticals here studied $(6 \pm 1-44 \pm 5$

$37 \mathrm{mg} \mathrm{g}^{-1}$ and $49 \pm 6-106 \pm 40 \mathrm{mg} \mathrm{g}^{-1}$, respectively). This may be related to the

38 comparatively higher incidence of mesopores in GACN, which might have positively

39 influenced its adsorptive performance. Moreover, the highest hydrophobic character and

40 degree of aromaticity of GACN could also have contributed to its adsorption capacity. On

41 the other hand, the performance of both GACs was significantly affected by the matrix in

42 the case of CBZ and SMX, with lower $q_{\mathrm{m}}$ in wastewater than in ultra-pure water. However,

43 the adsorption of PAR was not affected by the matrix. Electrostatic interactions and $\mathrm{pH}$

44 effects might also have influenced the adsorption of the pharmaceutical compounds in

45 wastewater.

47 Keywords: Industrial wastes, Waste management, Chemical activation, Agglomeration, Adsorptive water treatment, Emerging contaminants 


\section{Introduction}

Activated carbons (ACs) are carbonaceous materials with high adsorption capacity towards a vast number of organic and inorganic compounds, such as pharmaceuticals, pesticides, personal care products, dyes and metals (Rodriguez-Narvaez et al., 2017).

Commercial ACs, which are commonly produced from wood or coal (bituminous and subbituminous varieties), are available in powdered (PAC) or granular (GAC) formulations (Bandosz, 2006). GAC and PAC are used in water treatment, both presenting advantageous features and drawbacks depending on specific applications. PAC has the main advantage of, generally, possessing higher specific surface area $\left(S_{\mathrm{BET}}\right)$; however, it is usually applied in batch mode (due to inadequate particle size to be used in fixed-bed columns and difficult separation from the treated water in continuously stirred reactors). In the case of GAC, main advantages include its regeneration capability by thermal or chemical treatment and, therefore, its reuse, and the easiness of application in continuous mode, increasing the applicability in water treatment systems (Marsh and Rodríguez-Reinoso, 2006). The use of $\mathrm{AC}$ for the removal of organic contaminants from water, namely pharmaceuticals, is highly documented (e.g. Wang and Wang, 2016; Yang et al., 2017). Both PAC and GAC possess a great potential for the adsorption of these contaminants; yet, the use of PAC in wastewater treatment is usually associated to increased implementation and application costs and so GAC is generally the preferred option (Yang et al., 2017).

The production of AC from wastes has been proposed as an innovative and sustainable strategy (Silva et al., 2018), in line with an increasingly rigorous environmental legislation on the waste management that discourages disposal practices such as landfilling and incineration (European Commission, 2016 - Directive 2008/98/EC). Primary paper mill sludge (PS) is produced in large amounts, resulting from wastewater treatment in the 
73 pulp and paper industry, so constituting an important waste management issue within this 74 sector. Therefore, the use of PS to produce an added-value material such as AC can be 75 considered as a valuable circular economy option, aligned with the challenges of this 76 industry. Simultaneously, the use of PS as AC precursor has also proved to be 77 advantageous since its characteristics present low variability throughout time, pointing out 78 to its consistency to be used as raw material (Jaria et al., 2017). PAC produced from PS has 79 already been used for the removal of pharmaceuticals from water, presenting similar or 80 even higher adsorptive capacities than a commercial PAC (Jaria et al., in press). However, 81 due to the fibrous and brittle structure of PS (mostly constituted by cellulose), attempts to 82 use wastes with similar constitution to produce GAC have failed. In fact, a main problem of 83 waste-derived GACs is usually the low attrition resistance of the produced materials, which 84 may inhibit their use in adsorption beds (Smith et al., 2012). Different strategies have 85 already been proposed to produce hardened GACs with high attrition resistance, being 86 pelletization and/or the utilization of binder agents the most commonly used. The 87 introduction of a pelletization step is usually the approach when the AC is produced by 88 physical activation while the utilization of binders is usually the strategy in the case of 89 chemical activation (Carvalho et al., 2006). Several patents have been published on the 90 production of GAC employing binders such as urea-lignosulfonate (Blackmore, 1988) or 91 ammonium lignosulfonate (Kovach, 1975). Also, in the scientific literature, the utilization 92 of binders like humic acids (Lozano-Castelló et al., 2002) or clays (Carvalho et al., 2006) 93 has been proposed. A comparison of different binders was carried out by Lozano-Castelló 94 et al. (2002), who used a humic acid derived sodium salt, polyvinyl alcohol, a phenolic 95 resin, Teflon and an adhesive cellulose-based binder for the preparation of AC monoliths. 96 Also, Smith et al. (2012) compared the utilization of ammonium lignosulphonate, polyvinyl 
97 alcohol, phenolic resin, araldite resin, lignosulphonic acid, calcium salt, and carboxymethyl

98 cellulose sodium salt for the production of GACs from sewage sludge. The authors of both

99 studies (Lozano-Castelló et al., 2002; Smith et al., 2012) highlighted the importance of

100 selecting an appropriate binder so to avoid the deterioration of the adsorption performance

101 of the final material.

102 In the above described context, this work aimed to give a step forward in the

103 production of AC from PS and take on the challenge of obtaining, for the very first time, a

104 cellulosic waste-based GAC to be used in the removal of pharmaceuticals from water. For

105 the production of $\mathrm{GAC}$, ammonium lignosulfonate $(\mathrm{AL})$, which is a by-product derived

106 from the sulphite process applied in the manufacture of cellulose pulp, was used as binder

107 agent. The physicochemical characterization of the obtained GAC (PSA-PA) and of a

108 commercial GAC (GACN, results of which are taken as reference), was performed and

109 both adsorbents were tested under batch operation conditions for the adsorption of

110 pharmaceuticals from ultra-pure water and also from wastewater. The versatility of the

111 produced GAC was tested by studying the uptake of three pharmaceuticals from different

112 therapeutic classes and with different physicochemical properties: the antiepileptic

113 carbamazepine (CBZ), the antibiotic sulfamethoxazole (SMX), and the antidepressant

114 paroxetine (PAR).

115

116 2. Materials and Methods

117 2.1. Reagents

118 AL was used as binder agent and was kindly provided by Rayonier Advanced

119 Materials. KOH (EKA PELLETS, $\geq 86 \%$ ) was used as chemical activating agent. For the 120 washing step, $\mathrm{HCl}$ (AnalaR NORMAPUR, 37\%) was used. The pharmaceuticals studied in 
121 the adsorption tests were CBZ (Sigma Aldrich, 99\%), SMX (TCI, >98\%) and PAR

122 (paroxetine-hydrochloride, TCI, >98\%). These pharmaceuticals belong to three different

123 therapeutic classes (anticonvulsants, antibiotics and antidepressants, respectively) and

124 present different physicochemical properties (depicted in Table S1 in Supplementary

125 Material (SM)). The GAC used as reference (GACN, DARCO $12 \times 20$, particle size between

1260.8 and $1 \mathrm{~mm}$ ) was kindly provided by Norit.

127 All the solutions were prepared in ultra-pure water obtained from a Milli-Q

128 Millipore system (Milli-Q plus 185) or in wastewater (details on sampling and

129 characterization are presented in section 2.4).

\subsection{Production of GAC from $P S$}

For the production of a GAC using PS as raw material, several experimental

133 approaches were tested until obtaining a material with suitable hardness to withstand the

134 target application. In this context, the following factors were tested: type of activating

135 agent; impregnation ratio between the precursor, the activating agent and the binder agent;

136 impregnation order (activating agent followed by the binder agent or vice versa); and one-

137 or two-step pyrolysis (detailed procedures are shown in Table 1). The optimized production

138 methodology was achieved by a two-stage process (test $\mathrm{N}$ in Table 1). All the other tested

139 conditions failed to produce a granular material. Accordingly, in the first stage, $30 \mathrm{~g}$ of PS

140 was mixed with $70 \mathrm{~mL}$ of $\mathrm{AL}$ aqueous solution (at $35 \%$ ), resulting in a final PS:AL ratio

$141(w / w)$ of 6:5. The mixture was stirred overnight in a head-over-head shaker (80 rpm) and

142 left drying at room temperature followed by overnight oven-drying at $105^{\circ} \mathrm{C}$. The dried

143 mixture was pyrolysed under inert atmosphere $\left(\mathrm{N}_{2}\right)$ at $500^{\circ} \mathrm{C}$ for $10 \mathrm{~min}$. In a second stage, 144 each $10 \mathrm{~g}$ of the resultant carbon (named PSA) was activated with $20 \mathrm{~mL}$ of a solution of 
$145 \mathrm{KOH}($ at $50 \%)$, resulting in a PSA: $\mathrm{KOH}$ final ratio $(w / w)$ of $1: 1$. The mixture was stirred

146 for $1 \mathrm{~h}$ in an ultrasonic bath and oven-dried at $105^{\circ} \mathrm{C}$ overnight. This material was then

147 pyrolysed at $800^{\circ} \mathrm{C}$ for $150 \mathrm{~min}$, then washed with $1.2 \mathrm{M} \mathrm{HCl}$ and finally rinsed with

148 distilled water until neutral $\mathrm{pH}$ was reached. The final GAC, named PSA-PA, was crushed,

149 grounded and sieved to obtain a particle diameter between 0.5 and $1.0 \mathrm{~mm}$.

\subsection{Physicochemical characterization of PSA-PA and GACN}

The physicochemical analysis of PSA-PA and GACN was performed by means of

153 the determination of the total organic carbon (TOC) and inorganic carbon (IC); proximate

154 and ultimate analyses; $S_{\mathrm{BET}}$ and $\mathrm{Hg}$ porosimetry; determination of the surface functionality

155 by Boehm's titration; determination of the point of zero charge $\left(\mathrm{pH}_{p z c}\right)$; Fourier Transform

156 Infrared Spectroscopy with Attenuated Total Reflectance (FTIR-ATR); X-Ray

157 Photoelectron Spectroscopy (XPS) and Scanning Electron Microscopy (SEM). Detailed

158 procedures are explained in section 2 of SM.

\subsection{Wastewater sampling}

The performance of PSA-PA and GACN was evaluated in a real wastewater matrix

162 for the three considered pharmaceuticals. Wastewater samples were collected between May

1632017 and January 2018 (5 sampling campaigns) at a local sewage treatment plant (STP)

164 that treats domestic sewage (average daily flow of $39278 \mathrm{~m}^{3}$ day $^{-1}$; designed to serve

165159700 population equivalents). The STP operates both primary and biological treatments

166 and the collected wastewater samples corresponded to the final treated effluent (after

167 secondary decanting), which is discharged into the aquatic environment. After collection, 

173 in section 3 of SM.

wastewater samples were filtered through $0.45 \mu \mathrm{m}, 293 \mathrm{~mm}$ membrane filters (Gelman Sciences), stored at $4{ }^{\circ} \mathrm{C}$ until analysis and used within no longer than 15 days.

Wastewater samples were characterized by measuring conductivity (WTW meter), $\mathrm{pH}\left(\mathrm{pH} / \mathrm{mV} /{ }^{\circ} \mathrm{C}\right.$ meter $\left.\mathrm{pHenomenal}{ }^{\circledR} \mathrm{pH} 1100 \mathrm{~L}, \mathrm{VWR}\right)$ and TOC (Shimadzu, model TOC$\left.\mathrm{V}_{\mathrm{CPH}}, \mathrm{SSM}-5000 \mathrm{~A}\right)$. The properties of wastewater samples used in this work are presented

\subsection{Batch adsorption experiments with PSA-PA and GACN}

Kinetic and equilibrium batch experiments were performed to determine the adsorption of CBZ, SMX and PAR onto PSA-PA and GACN. For each pharmaceutical, solutions with a known initial concentration were prepared in both ultra-pure water and wastewater and stirred together with PSA-PA or GACN in an overhead shaker (Heidolph, Reax 2) at $80 \mathrm{rpm}$ and under controlled temperature $\left(25.0 \pm 0.1^{\circ} \mathrm{C}\right)$. After stirring, solutions' aliquots were filtered through $0.22 \mu \mathrm{m}$ PVDF filters (Whatman) and then analysed for the remaining concentration of pharmaceutical. For all the initial concentrations and pharmaceuticals, controls (containing the pharmaceutical solution, but not GAC) were run simultaneously with experiments, which were carried out in triplicate. The solutions were analysed by Micellar Electrokinetic Chromatography (MEKC) using a Beckman P/ACE MDQ instrument (Fullerton, CA, USA), equipped with a photodiode array detection system, according to the procedure described by Calisto et al. (2015). Briefly, a dynamically coated silica capillary with $40 \mathrm{~cm}(30 \mathrm{~cm}$ to the detection window) was used and the electrophoretic separation was accomplished at $25^{\circ} \mathrm{C}$, in direct polarity mode at $25 \mathrm{kV}$, during 5 min runs. Ethylvanillin was used as internal standard and sodium tetraborate was used to obtain better peak shape and resolution and higher repeatability, 
192 both spiked to all samples and standard solutions at final concentrations of $3.34 \mathrm{mg} \mathrm{L}^{-1}$ and $19310 \mathrm{mM}$, respectively. Detection was monitored at $214 \mathrm{~nm}$ for CBZ and at $200 \mathrm{~nm}$ for SMX 194 and PAR. Separation buffer consisted of $15 \mathrm{mM}$ of sodium tetraborate and $30 \mathrm{mM}$ of 195 sodium dodecyl sulfate. All the analyses were performed in triplicate.

196 For the kinetic studies, a predefined mass of each GAC was placed in polypropylene 197 tubes and put in contact with $40 \mathrm{~mL}$ of a $5 \mathrm{mg} \mathrm{L}^{-1}$ aqueous single solution of each 198 pharmaceutical. The concentrations of both PSA-PA and GACN were: in ultra-pure water, $19970 \mathrm{mg} \mathrm{L}^{-1}$ for CBZ, $50 \mathrm{mg} \mathrm{L}^{-1}$ for SMX, and $80 \mathrm{mg} \mathrm{L}^{-1}$ for PAR; in wastewater, $150 \mathrm{mg} \mathrm{L}^{-1}$ 200 for CBZ and PAR, and $200 \mathrm{mg} \mathrm{L}^{-1}$ for SMX. The solutions were shaken for different time 201 intervals between 0.5 and $72 \mathrm{~h}$. The adsorbed concentration of pharmaceutical onto each 202 GAC at time $t, q_{\mathrm{t}}\left(\mathrm{mg} \mathrm{g}^{-1}\right)$, was calculated by Eq. 1:

$$
q_{t}=\frac{\left(C_{0}-C_{t}\right) V}{m}
$$

204 where $C_{0}\left(\mathrm{mg} \mathrm{L}^{-1}\right)$ is the initial concentration of pharmaceutical, $C_{\mathrm{t}}\left(\mathrm{mg} \mathrm{L}^{-1}\right)$ is the 205 concentration of pharmaceutical in solution at time $t, V(\mathrm{~L})$ is the volume of solution and $m$ 206 is the mass of adsorbent $(\mathrm{g})$. The kinetic models used for fitting the experimental data are 207 presented in Table S3 (section 4 of SM); non-linear fittings were performed using 208 GraphPad Prism, version 5.

209 Equilibrium experiments were carried out to determine the adsorption isotherms, 210 which allow to conclude about the adsorption capacity of the adsorbents. Equilibrium tests 211 were performed by varying the initial concentration of the pharmaceutical and keeping the 212 adsorbent mass constant. Hence, $40 \mathrm{~mL}$ of single solutions of each pharmaceutical, with 213 concentrations varying between 5.0 and $0.5 \mathrm{mg} \mathrm{L}^{-1}$ (a minimum of 6 concentrations were 214 considered for each system), were added to a predefined mass of carbon. In ultra-pure 
215 water, the concentrations of PSA-PA were 50, 40 and $60 \mathrm{mg} \mathrm{L}^{-1}$ for the adsorption of CBZ,

216 SMX and PAR, respectively; and the concentrations of GACN were 50, 40 and $40 \mathrm{mg} \mathrm{L}^{-1}$

217 for the adsorption of CBZ, SMX and PAR, respectively. In wastewater, the PSA-PA

218 concentrations were of 125,150 and $100 \mathrm{mg} \mathrm{L}^{-1}$ for the adsorption of CBZ, SMX, and

219 PAR, respectively, while 125,150 and $80 \mathrm{mg} \mathrm{L}^{-1}$ of GACN were used for the adsorption of

220 CBZ, SMX, and PAR, respectively.

221 The adsorbed concentration of each pharmaceutical onto each GAC at the

222 equilibrium, $q_{\mathrm{e}}\left(\mathrm{mg} \mathrm{g}^{-1}\right)$ was calculated by Eq. 2 :

223

$$
q_{e}=\frac{\left(C_{0}-C_{e}\right) V}{m}
$$

224 where $C_{\mathrm{e}}\left(\mathrm{mg} \mathrm{L}^{-1}\right)$ is the concentration of pharmaceutical in solution at the equilibrium and 225 all the other variables are defined as in Eq. 1. The isotherm models used for describing the 226 experimental results are presented in Table S4 (section 4 of SM); non-linear fittings were 227 performed using GraphPad Prism, version 5.

229 3. Results

230 3.1. Physicochemical characterization of PSA-PA and GACN

231 3.1.1. Chemical characterization

232 PSA-PA and GACN present a high value of TOC, $72 \pm 2 \%$ and $79.7 \pm 0.8 \%$,

233 respectively, and a very low value of IC, $0.029 \pm 0.003 \%$ and $0.0204 \pm 0.0002 \%$,

234 respectively. Thus, the results obtained for TOC and IC were very similar for the produced

235 and reference GACs. Comparing the values for PSA-PA with those for the precursor (TOC

$236=29 \pm 1 \%$ and IC $=3.3 \pm 0.2 \%$ (Jaria et al., 2017)), the increase in the TOC content of the 237 produced carbon compared with the precursor is clear. 
239 that both materials possess a high content in fixed carbon (77 and 81\% for PSA-PA and

240 GACN, respectively). The percentage in heteroatoms is higher for PSA-PA, namely in

241 oxygen (13 and 6\% for PSA-PA and GACN, respectively). Also, the H/C ratio indicates

242 that GACN possesses a higher degree of aromaticity (lower H/C ratio) than PSA-PA.

243 Regarding FTIR-ATR analysis, the spectra for PSA-PA and for GACN are depicted

244 in Figure S1 (section 2 of SM). The spectrum of PSA-PA (Figure S1a) shows peaks at 1530

$245 \mathrm{~cm}^{-1}$, which is characteristic of aromatic compounds and can be also associated to

246 secondary amide $\mathrm{N}-\mathrm{H}$ and $\mathrm{C}-\mathrm{N}$ bending $\left(1560-1530 \mathrm{~cm}^{-1}\right.$ ) (Stuart, 2004). The bands at

2471100 and $1180 \mathrm{~cm}^{-1}$ might be associated with secondary alcohols $\mathrm{C}-\mathrm{O}$ stretch and the bands

248 between 3800 and $3600 \mathrm{~cm}^{-1}$ can be assigned to alcohol/phenol O-H stretching (Coates,

249 2000; Stuart, 2004). GACN spectrum (Figure S1b) revealed a broad band at $1125 \mathrm{~cm}^{-1}$ and

250 a band at $1530 \mathrm{~cm}^{-1}$, which can be associated to secondary alcohols $\mathrm{C}-\mathrm{O}$ stretch and to the

251 aromaticity of the material, respectively. Bands at 3605 and $3720 \mathrm{~cm}^{-1}$ evidence the

252 presence of alcohol/phenol O-H stretching (Coates, 2000).

253 The determination of the surface functional groups (Table 3) indicated that both

254 GACs have an acidic nature. This was confirmed by the values of $\mathrm{pH}_{p z c}$ determined for

255 PSA-PA and GACN (Table 3). Also, from results in Table 3, it is possible to infer that the

256 oxygen atoms present in both GACs are likely present in the form of carboxyl (particularly

257 for $\mathrm{GACN}$ ) and phenol groups, with lower incidence of lactones.

258 To complement the surface functionality characterization, XPS analysis was

259 performed and the results are presented in Table 4. The results showed that PSA-PA

260 possesses a high amount of oxygen compared with GACN. In fact, the XPS data indicate

261 contents of $74.76 \%$ of carbon, $17.32 \%$ of oxygen and $2.34 \%$ of nitrogen for PSA-PA, and 
263 from the ultimate analysis (Table 2). By deconvolution of the $\mathrm{C} 1 \mathrm{~s}$ region, the prevalence of

264 graphitic $\mathrm{C} \mathrm{sp}{ }^{2}$ is evident (especially for $\mathrm{GACN}$ ), along with the presence of $\mathrm{C}-\mathrm{C} \mathrm{sp}^{3}$ bonds

265 associated to phenolic, alcoholic and etheric carbons at the edge of the graphene layer

266 (especially for PSA-PA) (Nielsen et al., 2014; Velo-Gala et al., 2014). These results are

267 coincident with the FTIR-ATR spectra, presenting bands characteristic of alcohols

268 (between 3800 and $3600 \mathrm{~cm}^{-1}$ ), mainly observed in PSA-PA spectrum. Peaks associated to

269 carbonyl or quinones and to carboxyl or ether groups are present in relatively similar

270 percentages for both GACs (peaks 3 and 4, respectively, for C 1s). These results do not

271 seem to be in agreement with the Boehm's titration results, since in those the carboxylic

272 groups are in greater amount, especially in the case of GACN. These differences can be due

273 to the fact that XPS is a surface technique while Boehm's titration is a bulk technique. Both

274 spectra also present a peak at $291 \mathrm{eV}$, which can be associated to $\mathrm{C} \pi-\pi^{*}$ transition (Velo-

275 Gala et al., 2014). Concerning the O 1s spectra, PSA-PA presents a peak at 535.5 (peak 3)

276 which may be attributed to chemisorbed oxygen (Velo-Gala et al., 2014). Also, it presents a

277 peak at $531 \mathrm{eV}$ which can be assigned to $\mathrm{C}=\mathrm{O}$ bonding in quinones and carbonyl groups,

278 and a peak around $533 \mathrm{eV}$ assigned to oxygen atoms of hydroxyl groups and to lactones

279 and anhydrides. These two peaks (at 531 and $533 \mathrm{eV}$ ) are likewise in the GACN XPS

280 spectrum, which also presents a peak at $534.4 \mathrm{eV}$ that may be associated to oxygen of

281 carboxyl groups, which is coincident with the Boehm's titrations results.

282 For PSA-PA it was also performed the fitting of the peaks associated to N 1s. In

283 fact, comparing the overall spectra of the two GACs (Figure S2 in section 2 of SM) it is

284 possible to clearly observe a peak in the $\mathrm{N}$ 1s zone for PSA-PA, while for GACN this peak

285 is not noticeable. This is consistent with the higher N content of PSA-PA in comparison 
with GACN, as revealed by the ultimate analysis (Table 2). The fitting indicates the

287 presence of two peaks, at 398.0 and $400.1 \mathrm{eV}$, which might be attributed to pyridinic and 288 pyrrolic N, respectively (Li et al., 2014; Wei et al., 2016).

\subsubsection{Physical characterization}

For the study of the textural features of the materials, nitrogen adsorption isotherms

292 and SEM were used as characterization techniques. The results of $S_{\mathrm{BET}}$ and $\mathrm{Hg}$ porosimetry

293 are presented in Table 5. For both GACs, $S_{\mathrm{BET}}$ and micropore volume $\left(W_{0}\right)$ values are very

294 similar; however, GACN possesses larger total pore volume $\left(V_{p}\right)$ and average pore diameter

295 (D) values than PSA-PA, which might have important implications in the adsorptive

296 performance of the materials, as explained below (see section 3.2). Observing the pore size

297 distribution (Figure 1), it is evident that PSA-PA possesses a narrower pore size

298 distribution with prevalence of pores with $5 \mathrm{~nm}$ of diameter and smaller, whilst GACN

299 presents a broader distribution, including a significant amount of larger pore sizes in the

300 mesopores' range $(2-50 \mathrm{~nm})$. This may be an interesting feature of PSA-PA considering the

301 selective adsorption of molecules with different sizes. On the other hand, the apparent

302 density is similar for both materials, although it is slightly superior in the case of GACN.

303 The surface morphological structure of the two GACs was analysed by SEM

304 (Figure 2). It is interesting to observe that, at the lowest magnifications, GACN appears to

305 have a more homogeneous morphology but, at higher magnifications, the structure becomes

306 rougher and the porosity is revealed. In the case of PSA-PA, at the lowest magnifications, a

307 more disordered structure (possibly due to fragments of fibres that have not been destroyed)

308 can be observed, but at higher magnification, porosity is also clearly observed. 


\section{3.2. Batch adsorption experiments with PSA-PA and GACN}

\section{$312 \quad 3.2 .1$ Kinetic studies}

313 The graphical representation of experimental and model results, and the parameters

314 of the fitted models for the adsorption kinetics of CBZ, SMX and PAR onto the two studied

315 GACs (PSA-PA and GACN) in ultra-pure water and in wastewater are presented in Figure

3163 and Table 6, respectively. The kinetic models used to describe the adsorption

317 experimental results were the pseudo-first order (PFO) and pseudo-second order (PSO)

318 models (Table S3, section 4 in SM).

319 As it may be seen in Table 6, the fittings to the PFO and the PSO models presented

$320 R^{2}$ values above 0.90 , except for the adsorption kinetics of PAR onto GACN, in ultra-pure

321 water. Therefore, both models (PFO and PSO) were considered to reasonably describe the

322 experimental data. In general terms, it may be said that, for CBZ and SMX, the results were

323 slightly better described by the PSO model, while PFO model was the most adequate to

324 describe the adsorption kinetics of PAR.

325 In relation to the rate constants $k_{1}$ and $k_{2}$, the values vary between $10^{-6}$ and $10^{-3}$

$326\left(\mathrm{~min}^{-1}\right.$ or $\mathrm{g} \mathrm{mg}^{-1} \mathrm{~min}^{-1}$, respectively). These low values are in agreement with the relatively

327 long equilibrium times (above $24 \mathrm{~h}$ ) here determined. It must be taken into account that,

328 due to the particle size of GACs, adsorption kinetics are usually slower than onto powdered

329 materials. Nevertheless, it is possible to observe that GACN presents a slightly faster

330 adsorption rate than PSA-PA for CBZ in ultra-pure water (2 times higher $k_{2}$ ), and for PAR

331 in ultra-pure and wastewater (3.6 and 3.25 times higher $k_{1}$, respectively), while PSA-PA

332 presents a faster adsorption rate than GACN in the case of $\mathrm{CBZ}$ in wastewater (4 times 
333 higher $k_{2}$ ) and SMX in both matrices (3.5 times higher $k_{2}$ in ultra-pure water and 22 times

334 higher $k_{2}$ in wastewater).

\subsubsection{Equilibrium studies}

Experimental equilibrium and model results, and the corresponding parameters of the non-linear fittings, for the adsorption of CBZ, SMX and PAR onto PSA-PA and GACN in ultra-pure water and in wastewater are presented in Figure 4 and Table 6, respectively. The isotherm models used to describe the equilibrium experimental results were Langmuir, Freundlich and Sips models (Table S4, section 4 in SM).

Equilibrium results of the three pharmaceuticals onto PSA-PA, either in ultra-pure or wastewater, were better described by the Langmuir and the Sips models than by the Freundlich model. In the case of GACN, the Sips model revealed to be not suitable to model the experimental data, with most of the fittings being ambiguous. Considering the other tested models, even though the Freundlich equation has presented fittings with $R^{2}$ values slightly higher in some cases, it can be said that the equilibrium results were mostly best fitted by the Langmuir isotherm. Thus, to allow the comparison of the results of all the studied systems, the Langmuir model was selected.

The Langmuir maximum adsorption capacity $\left(q_{\mathrm{m}}\right)$ of GACN is higher than that of PSA-PA. For the latter, $q_{\mathrm{m}}$ values range from $24 \pm 5$ to $44 \pm 5 \mathrm{mg} \mathrm{g}^{-1}$ and from $6 \pm 1$ to $34 \pm$ $9 \mathrm{mg} \mathrm{g}^{-1}$, in ultra-pure water and wastewater, respectively. Meanwhile, for GACN, the $q_{\mathrm{m}}$ range from $64 \pm 12$ to $98 \pm 17 \mathrm{mg} \mathrm{g}^{-1}$ and from $49 \pm 6$ to $106 \pm 40 \mathrm{mg} \mathrm{g}^{-1}$, in ultra-pure water and wastewater, respectively. Both GACs present better performance for CBZ and SMX in ultra-pure water than in wastewater. However, the effect of the aqueous matrix in $q_{\mathrm{m}}$ was not remarkable for the adsorption of PAR, particularly in the case of PSA-PA. 
As it may be seen in Figure 4, the adsorption of CBZ onto GACN was much lower

357 in wastewater than in ultra-pure water. The decrease was not so evident in the adsorption of 358 CBZ onto PSA-PA, but, still, $q_{\mathrm{m}}$ decreased from $24 \pm 5 \mathrm{mg} \mathrm{g}^{-1}$ (in ultra-pure water) to $10 \pm$ $3591 \mathrm{mg} \mathrm{g}^{-1}$ (in wastewater). The $q_{\mathrm{m}}$ determined for the adsorption of SMX onto both carbons 360 in wastewater was lower than in ultra-pure water. However, while in the case of GACN the

361 adsorption capacity decreased to a half (from $98 \pm 17$ to $49 \pm 6 \mathrm{mg} \mathrm{g}^{-1}$ ), the decrease was

362 more accentuated for PSA-PA (from $44 \pm 5$ to $6 \pm 1 \mathrm{mg} \mathrm{g}^{-1}$ ). Finally, as evidenced in Figure

3634 and confirmed by the parameters in Table 6, the adsorption of PAR onto both carbons

364 remained mostly the same in wastewater and in ultra-pure water.

\section{Discussion}

Analysing the structural properties of both carbons (Table 5), it is possible to see that $S_{\mathrm{BET}}$ and $W_{0}$ are very similar, indicating that these parameters are probably not the 369 main factors influencing the differences observed between the GACs with respect to the 370 adsorption of the studied pharmaceuticals. However, $V_{\mathrm{p}}$ and $D$ of GACN are significantly

371 superior to those of PSA-PA. Taking into account the similar value of the $W_{0}$ for both

372 GACs, a larger $V_{\mathrm{p}}$ in GACN indicates that this carbon has a higher presence of mesopores

373 in its porous structure. Furthermore, the pore size distribution (Figure 1) clearly evidences

374 that GACN has a broader distribution of the pore sizes in the range of mesopores (2-50

$375 \mathrm{~nm}$ ), while PSA-PA has a higher presence of pores below $5 \mathrm{~nm}$. Therefore, the mesoporous 376 character of the GACN could explain to a certain extent the better results of the adsorption 377 experiments for this adsorbent. This might be due not only to the importance of mesopores 378 as channels that guarantee the accessibility to micropores but also to the molecular sizes of 379 the studied pharmaceuticals, which are very close to the PSA-PA average pore diameter 
381 et al., 2014)). The influence of these parameters in the adsorption of pharmaceuticals onto

382 waste-based activated carbons has also been reported by Mestre et al. (2009). On the other

383 hand, for PSA-PA, which possesses a higher amount of functional groups (Table 3), surface

384 interactions are more likely to be present.

385 Considering the adsorption of CBZ, for both GACs and matrices, the compound is

386 mainly in the neutral form (see $\mathrm{p} K_{a}$ values in Table $\mathrm{S} 1$, in section 1 of $\mathrm{SM}$ ), which indicates

387 that electrostatic forces do not play a significant role in the adsorption process. Also, CBZ

388 has a low solubility in water at $25^{\circ} \mathrm{C}$ and a high $\log K_{\text {ow }}$ (Table S1, in section 1 of SM), and

389 therefore, hydrophobic interactions may play an important role mainly in ultra-pure water.

390 Considering that the adsorption of CBZ onto GACN is higher than in PSA-PA, GACN

391 might be more hydrophobic than PSA-PA, since it possesses fewer surface functional

392 groups and higher prevalence of graphitic carbon and thus a higher degree of aromaticity

393 (Tables 2-4). In this context, and particularly for GACN, $\pi-\pi$ interactions may occur

394 between CBZ benzene rings (that act as a $\pi$-electron acceptor due to the amide

395 functionality, which functions as an electron withdrawing group (Cai and Larese-Casanova, 396 2014)) and the aromatic benzene rings of the graphitic part of the carbon that can act as $\pi-$

397 electron donor groups, forming a $\pi-\pi$ electron donor-acceptor complex.

398 Relative to the adsorption of SMX and similarly to CBZ, $\pi-\pi$ interactions can occur

399 between the $\pi$-donor hydroxyl substituent groups of the benzene rings and the $\pi$-acceptor of

400 SMX amino group and N-heteroaromatic rings (Zhang et al., 2010). This last interaction

401 may have contributed, in part, to the higher adsorption capacity of SMX onto GACN, since

402 according to the $\mathrm{H} / \mathrm{C}$ ratio (Table 2) and as above referred, this carbon presents a higher

403 degree of aromaticity and, therefore, of graphitic carbon (as confirmed by the XPS results 
404 (Table 4)). The reduction of the adsorption capacity of the GACs towards SMX from ultra-

405 pure water to wastewater can be explained by the $\mathrm{pH}$ change, since in the case of the

406 wastewater matrix ( $\mathrm{pH}$ between 7 and 8), both GACs present a negative net charge $\left(\mathrm{pH}_{p z c}\right.$

407 between 4 and 5) and SMX species are mostly present in the anionic form (see $\mathrm{p} K_{a}$ values

408 in Table S1, in section 1 of SM), and therefore, electrostatic repulsion is likely to occur.

409 Besides, SMX is the pharmaceutical possessing the lowest $\log K_{o w}$ value (see Table $\mathrm{S} 1$, in

410 section 1 of SM), being the less adsorbed pharmaceutical in this condition.

411 For the adsorption of PAR onto both GACs, no significant differences were verified

412 between adsorption capacities in ultra-pure water and wastewater (Figure 4). In fact, PAR

413 is mostly present in its positive form in both matrices (see $\mathrm{p} K_{a}$ values in Table $\mathrm{S} 1$, in

414 section 1 of SM) and thus, in the case of wastewater, electrostatic interactions have

415 certainly an important role in the adsorption process, balancing competitive effects that

416 may affect the carbons' adsorption capacity. Also, PAR possesses a high value of $\log K_{\text {ow }}$

417 (see Table S1, in section 1 of SM), which is considered to positively influencing the

418 adsorption onto the nonpolar surface of activated carbons (Çeçen and Aktaş, 2011).

419 All the target pharmaceuticals possess hydrogen-bonding acceptors, namely, three $\mathrm{H}$

420 bond acceptors in CBZ, four in PAR and six in SMX (Table S1, in section 1 of SM).

421 Analysing the $q_{\mathrm{m}}$ values for the three pharmaceuticals in ultra-pure water for PSA-PA, it is

422 possible to observe some correlation with the number of hydrogen-bonding acceptors as

423 PSA-PA shows a higher adsorption capacity for SMX (the pharmaceutical with higher

424 hydrogen bond acceptors), and a smaller adsorption capacity for CBZ (the one possessing

425 the lowest number of hydrogen bond acceptors). This can point out hydrogen bonding as

426 one of the possible mechanisms occurring in the adsorption of these pharmaceuticals in

427 ultra-pure water onto PSA-PA. This tendency, however, is not maintained in the 
wastewater matrix, where the highest adsorption capacity is obtained for PAR, followed by

$429 \mathrm{CBZ}$, and SMX. Thus, as referred above, $\mathrm{pH}$ effects and electrostatic interactions appear to 430 be important factors ruling the adsorption of the studied pharmaceuticals in wastewater.

431 5. Conclusions

432 In this work, fourteen different procedures were tested to accomplish the challenge

433 of producing a GAC from an industrial waste. The production of a GAC was only possible

434 using AL as binder agent and it was successfully achieved by a procedure involving a two-

435 step pyrolysis. Then, the resulting material (PSA-PA) was applied for the adsorptive

436 removal of CBZ, SMX and PAR from water. It was found that PSA-PA exhibits very

437 similar physicochemical properties to a commercial GAC (GACN, used as reference) in

438 what concerns $S_{\mathrm{BET}}$, micropore volumes, predominance of surface phenol and carboxylic

439 groups and acidic $\mathrm{pH}_{p z c}$. However, PSA-PA possesses a total pore volume and an average

440 pore diameter twice lower than GACN, indicating a significantly higher presence of

441 mesopores in GACN, which may be responsible for the lower adsorption capacity of PSA-

442 PA towards the considered pharmaceuticals. On the other hand, the adsorption capacity of

443 PSA-PA and GACN was strongly affected by the matrix, with a significant decrease in the

444 adsorption of CBZ and SMX from wastewater as compared with ultra-pure water.

445 However, the same effect was not verified for the adsorption of PAR, which could be

446 explained by $\mathrm{pH}$ effects and electrostatic interactions. Although PSA-PA showed lower

447 adsorption capacities than GACN for ultra-pure water and wastewater tests, it should be

448 considered that the produced adsorbent is a waste-based carbon, and other parameters apart

449 from the maximum adsorption capacity (such as its dynamic behaviour and cost) need to be

450 studied in detail in future works. For example, relatively fast adsorption rate for some of the

451 studied cases was here verified, indicating the potential of PSA-PA. Overall, this study 
452 represents a step forward in the utilization of PS as raw material for GAC production,

453 enabling its application in fixed-bed systems for the adsorption of pharmaceuticals, which

454 will be considered in future work of this research group.

\section{Acknowledgments}

456 This work was funded by FEDER through COMPETE 2020 and by national funds

457 through FCT by the research project PTDC/AAG-TEC/1762/2014. Vânia Calisto and

458 Marta Otero also thank FCT for a postdoctoral grant (SFRH/BPD/78645/2011) and support

459 by the FCT Investigator Program (IF/00314/2015), respectively. Thanks are also due for the

460 financial support to CESAM (UID/AMB/50017-POCI-01-0145-FEDER-007638), to

461 FCT/MCTES through national funds (PIDDAC), and the co-funding by the FEDER, within

462 the PT2020 Partnership Agreement and Compete 2020. Milton Fontes and workers of

463 Aveiro’s STP (Águas do Centro Litoral) are gratefully acknowledged for assistance on the

464 effluent sampling campaigns. The authors also thank Rayonier Advanced Materials for

465 kindly providing the binder agent used in this work.

466

467 References

468 Aygün, A., Yenisoy-Karakas, S., Duman, I., 2003. Production of granular activated carbon from

469 fruit stones and nutshells and evaluation of their physical, chemical and adsorption properties.

470 Micropor Mesopor Mat 66, 189-195.

471 Bae, W., Kim, J., Chung, J., 2014. Production of granular activated carbon from food processing

472 wastes (walnut shells and jujube seeds) and its adsorptive properties. J Air Waste Ma 64, 879-886.

473 Bandosz, T.J., 2006. Activated Carbon Surfaces in Environmental Remediation, first

474 edition, Elsevier, New York. 
475 Belhachemi, M., Addoun, F., 2011. Comparative adsorption isotherms and modeling of methylene

476 blue onto activated carbons. Applied Water Science 1, 111-117.

477 Blackmore, K.A.E., 1988. Lignosulfonate/urea binder for particulate composites. US Patent

478 4,786,438, filed August 10, 1987 and issued November 22, 1988.

479 Cai, N., Larese-Casanova, P., 2014. Sorption of carbamazepine by commercial graphene oxides: a

480 comparative study with granular activated carbon and multiwalled carbon nanotubes. J Colloid

481 Interf Sci 426, 152-161.

482 Calisto, V., Ferreira, C.I., Oliveira, J.A., Otero, M., Esteves, V.I., 2015. Adsorptive removal of

483 pharmaceuticals from water by commercial and waste-based carbons. J Environ Manage 152, 83-

48490.

485 Carvalho, A.P., Mestre, A.S., Pires, J., Pinto, M.L., Rosa, M.E., 2006. Granular activated carbons

486 from powdered samples using clays as binders for the adsorption of organic vapours. Micropor

487 Mesopor Mat. 93, 226-231.

488 Çeçen, F., Aktaş, Ö., 2011. Integration of Activated Carbon Adsorption and Biological Processes in

489 Wastewater Treatment, in Activated Carbon for Water and Wastewater Treatment: Integration of

490 Adsorption and Biological Treatment. Wiley-VCH Verlag GmbH \& Co. KGaA, Weinheim,

491 Germany.

492 Coates, J., 2000. Interpretation of Infrared Spectra - A Practical Approach, in: Encyclopedia of

493 Analytical Chemistry. John Wiley \& Sons Ltd, Chichester.

494 Ebadi, A., Soltan Mohammadzadeh, J.S., Khudiev, A., 2009. What is the correct form of BET

495 isotherm for modeling liquid phase adsorption? Adsorption 15, 65-73.

496 European Commission, 2016. Directive 2008/98/EC on Waste (Waste Framework Directive).

497 http://ec.europa.eu/environment/waste/framework/ (Accessed on September 2018).

498 Foo, K.Y., Hameed, B.H., 2010. Insights into the modeling of adsorption isotherm systems. Chem

499 Eng J 156, 2-10. 
501 treatment as raw material to produce carbon adsorbents: An alternative waste management strategy.

502 J Environ Manage 188, 203-211.

503 Jaria, G., Silva, C.P., Oliveira, J.A.B.P., Santos, S.M., Gil, M. V, Otero, M., Calisto, V., Esteves,

504 V.I., In Press. Production of highly efficient activated carbons from industrial wastes for the

505 removal of pharmaceuticals from water-A full factorial design. J Hazard Mater.

506 Kim, J.-W., Sohn, M.-H., Kim, D.-S., Sohn, S.-M., Kwon, Y.-S., 2001. Production of granular

507 activated carbon from waste walnut shell and its adsorption characteristics for $\mathrm{Cu} 2+$ ion. $\mathrm{J}$ Hazard

508 Mater B 85, 301-315.

509 Kovach, J. L., 1975. Hard granular activated carbon and preparation from a carbonaceous material a

510 binder and a inorganic activating agent. US Patent 3,864,277, filed August 14, 1972, and issued at

511 February 41975.

512 Largitte, L., Pasquier, R., 2016. A review of the kinetics adsorption models and their application to

513 the adsorption of lead by an activated carbon. Chemical Engineering Research and Design 109, $514 \quad 495-504$.

515 Li, Z., Xu, Z., Wang, H., Ding, J., Zahiri, B., Holt, C.M.B., Tan, X., Mitlin, D., 2014. Colossal

516 pseudocapacitance in a high functionality-high surface area carbon anode doubles the energy of an 517 asymmetric supercapacitor. Energy Environ Sci 7, 1708-1718.

518 Liu, Y.a.S.L., 2008. From Langmuir Kinetics to First- and Second-Order Rate Equations for 519 Adsorption. Langmuir 24, 11625-11630.

520 Lozano-Castelló, D., Cazorla-Amorós, D., Linares-Solano, A., Quinn, D.F., 2002. Activated carbon 521 monoliths for methane storage: influence of binder. Carbon, 40, 2817-2825.

522 Marczewski, A.W., 2007. Kinetics and equilibrium of adsorption of organic solutes on mesoporous 523 carbons. Appl Surf Sci 253, 5818-5826.

524 Markovic, D.D., Lekic, B.M., Rajakovic-Ognjanovic, V.N., Onjia, A.E., Rajakovic, L.V., 2014. A 525 new approach in regression analysis for modeling adsorption isotherms. Sci World J 2014, 930879. 
Marsh, H., Rodríguez-Reinoso, F., 2006. Activated Carbon, First ed. Elsevier, England.

527 Mestre, A.S., Pires, J., Nogueira, J.M.F., Parra, J.B., Carvalho, A.P., Ania, C.O., 2009. Waste-

528 derived activated carbons for removal of ibuprofen from solution: Role of surface chemistry and

529 pore structure. Bioresource Technol 100, 1720-1726.

530 Nielsen, L., Biggs, M.J., Skinner, W., Bandosz, T.J., 2014. The effects of activated carbon surface

531 features on the reactive adsorption of carbamazepine and sulfamethoxazole. Carbon 80, 419-432.

532 Pan, B.C., Xiong, Y., Su, Q., Li, A.M., Chen, J.L., Zhang, Q.X., 2003. Role of amination of a

533 polymeric adsorbent on phenol adsorption from aqueous solution. Chemosphere 51, 953-962.

534 Park, K.-H., Balathanigaimani, M.S., Shim, W.-G., Lee, J.-W., Moon, H., 2010. Adsorption

535 characteristics of phenol on novel corn grain-based activated carbons. Micropor Mesopor Mat 127,

$536 \quad 1-8$

537 Qiu, H., Lv, L., Pan, B.-c., Zhang, Q.-j., Zhang, W.-m., Zhang, Q.-x., 2009. Critical review in

538 adsorption kinetic models. J Zhejiang Univ-SC A 10, 716-724.

539 Rodriguez-Narvaez, O.M., Peralta-Hernandez, J.M., Goonetilleke, A., Bandala, E.R., 2017.

540 Treatment technologies for emerging contaminants in water: A review. Chem Eng J 323, 361-380.

541 Silva, C.P., Jaria, G., Otero, M., Esteves, V.I., Calisto, V., 2018. Waste-based alternative adsorbents

542 for the remediation of pharmaceutical contaminated waters: Has a step forward already been taken?

543 Bioresource Technol 250, 888-901.

544 Smith, K.M., Fowler, G.D., Pullket, S., Graham, N.J.D., 2012. The production of attrition resistant,

545 sewage-sludge derived, granular activated carbon. Sep Purif Technol 98, 240-248.

546 Stuart, B., 2004. Infrared Spectroscopy : Fundamentals and Applications. Wiley, Chichester, West

547 Sussex, England.

548 Tan, K.L., Hameed, B.H., 2017. Insight into the adsorption kinetics models for the removal of

549 contaminants from aqueous solutions. J Taiwan Inst Chem E 74, 25-48.

550 Velo-Gala, I., López-Peñalver, J.J., Sánchez-Polo, M., Rivera-Utrilla, J., 2014. Surface

551 modifications of activated carbon by gamma irradiation. Carbon 67, 236-249. 
552 Wang, J., Wang, S., 2016. Removal of pharmaceuticals and personal care products (PPCPs) from

553 wastewater: A review. J Environ Manage 182, 620-640.

554 Wei, T., Zhang, Q., Wei, X., Gao, Y., Li, H., 2016. A Facile and Low-Cost Route to Heteroatom

555 Doped Porous Carbon Derived from Broussonetia Papyrifera Bark with Excellent Supercapacitance

556 and $\mathrm{CO}_{2}$ Capture Performance. Sci. Rep. 6, 22646.

557 Yang, R.T., 2003. Adsorbents: Fundamentals and Applications. John Wiley \& Sons, Inc., New

558 Jersey.

559 Yang, Y., Ok, Y.S., Kim, K.H., Kwon, E.E., Tsang, Y.F., 2017. Occurrences and removal of

560 pharmaceuticals and personal care products (PPCPs) in drinking water and water/sewage treatment

561 plants: A review. Sci Total Environ 596-597, 303-320.

562 Zhang, D., Pan, B., Zhang, H., Ning, P., Xing, B., 2010. Contribution of Different

563 Sulfamethoxazole Species to Their Overall Adsorption on Functionalized Carbon Nanotubes.

564 Environ Sci Tech 44, 3806-3811. 
Table 1 - Experimental conditions tested for the production of a GAC using primary paper mill sludge (PS) as precursor, ammonium lignosulfonate (AL) as binder agent and different chemical activating agents (AA).

\begin{tabular}{|c|c|c|c|}
\hline Test & $\begin{array}{c}\text { Activating agent } \\
\text { (AA) }\end{array}$ & $\begin{array}{c}\text { Ratio } \\
(w / w / w)\end{array}$ & Procedure \\
\hline A & $\mathrm{K}_{2} \mathrm{CO}_{3}$ & $10: 10: 1^{\mathrm{a}}$ & AL was mixed in different proportions with PS and with the AA solution. It \\
\hline B & $\mathrm{K}_{2} \mathrm{CO}_{3}$ & $4: 4: 1^{\mathrm{a}}$ & was left to dry and pyrolysed at $800^{\circ} \mathrm{C}$ for $150 \mathrm{~min}$. From tests A to C, AL \\
\hline $\mathbf{C}$ & $\mathrm{K}_{2} \mathrm{CO}_{3}$ & $2: 2: 1^{\mathrm{a}}$ & was added as an aqueous solution; from tests $\mathrm{D}$ to $\mathrm{H}, \mathrm{AL}$ was added as a \\
\hline $\mathbf{D}$ & $\mathrm{K}_{2} \mathrm{CO}_{3}$ & $10: 10: 1^{\mathrm{a}}$ & powder. \\
\hline $\mathbf{E}$ & $\mathrm{K}_{2} \mathrm{CO}_{3}$ & $4: 4: 1^{\mathrm{a}}$ & \\
\hline $\mathbf{F}$ & $\mathrm{K}_{2} \mathrm{CO}_{3}$ & $2: 2: 1^{\mathrm{a}}$ & \\
\hline G & $\mathrm{KOH}$ & $2: 2: 1^{\mathrm{a}}$ & \\
\hline $\mathbf{H}$ & $\mathrm{H}_{3} \mathrm{PO}_{4}$ & $2: 2: 1^{a}$ & \\
\hline I & $\mathrm{KOH}$ & $2: 2: 1^{a}$ & $\begin{array}{l}\text { PS was firstly washed with } \mathrm{HCl} 1.2 \mathrm{M} \text { and then with distilled water until } \\
\text { neutral } \mathrm{pH} \text { was reached, for the removal of ashes. Next, washed PS was mixed } \\
\text { with } \mathrm{AL} \text { (in powder) and AA, left to dry and pyrolysed at } 800^{\circ} \mathrm{C} \text { for } 150 \mathrm{~min} \text {. }\end{array}$ \\
\hline $\mathbf{J}$ & $\mathrm{KOH}$ & $2: 2: 1^{a}$ & $\begin{array}{l}\text { PS was mixed with AL (in solution) in an overhead shaker for } 12 \mathrm{~h} \text {. After } \\
\text { drying at room temperature, it was added to AA, left to dry and pyrolysed at } \\
800^{\circ} \mathrm{C} \text { for } 150 \mathrm{~min} \text {. }\end{array}$ \\
\hline $\mathbf{K}$ & $\begin{array}{l}\mathrm{KOH} \\
\mathrm{K}_{2} \mathrm{CO}_{3}\end{array}$ & $\begin{array}{l}2: 2: 1^{\mathrm{a}} \\
2: 2: 1^{\mathrm{a}}\end{array}$ & $\begin{array}{l}\text { PS was mixed with AA and left to dry at room temperature. Next, AL (in } \\
\text { solution) was added and the mixture was dried and pyrolysed at } 800^{\circ} \mathrm{C} \text { for } \\
150 \text { min. }\end{array}$ \\
\hline $\begin{array}{l}\mathbf{M} \\
\mathbf{N}\end{array}$ & $\begin{array}{c}\mathrm{K}_{2} \mathrm{CO}_{3} \\
\mathrm{KOH}\end{array}$ & $\begin{array}{l}6: 5^{\mathrm{b}} \text { and } 1: 1^{\mathrm{c}} \\
6: 5^{\mathrm{b}} \text { and } 1: 1^{\mathrm{c}}\end{array}$ & $\begin{array}{l}\text { PS was mixed with the } \mathrm{AL} \text { (in solution), dried and pyrolysed at } 500{ }^{\circ} \mathrm{C} \text { for } 10 \\
\text { min. The obtained carbon (PSA) was then mixed with the AA at a } 1: 1 \text { ratio } \\
\text { (PSA:AA, w:w). This mixture was shaken during } 1 \mathrm{~h} \text { in an ultrasonic bath, } \\
\text { dried and pyrolysed at } 800^{\circ} \mathrm{C} \text { for } 150 \text { min. The final carbon (PSA-PA) was } \\
\text { then washed with } \mathrm{HCl} 1.2 \mathrm{M} \text { and distilled water until neutral pH was reached. }\end{array}$ \\
\hline
\end{tabular}

${ }^{\mathrm{a}} \mathrm{PS}: \mathrm{AA}: \mathrm{AL}$ ratio; ${ }^{\mathrm{b}} \mathrm{PS}: \mathrm{AL}$ ratio; ${ }^{\mathrm{P}} \mathrm{PA}$ :AA ratio

Note: All the pyrolysis experiments were carried out under $\mathrm{N}_{2}$ atmosphere. 
Table 2 - Proximate and ultimate analyses for PSA-PA and GACN.

\begin{tabular}{ccc}
\hline & PSA-PA & GACN \\
\hline Proximate Analysis $(\boldsymbol{d} \boldsymbol{b})$ & & \\
Moisture $(w t \%)$ & 8 & 8 \\
Volatile Matter $(w t \%)$ & 13 & 6 \\
Fixed Carbon $(F C)$ & 77 & 81 \\
Ash $(w t \%)$ & 9 & 13 \\
$F C / V M$ & 6 & 14 \\
\hline Ultimate Analysis $(\boldsymbol{d a b})$ & & \\
$\% C$ & 81.2 & 92.4 \\
$\% H$ & 1.9 & 0.75 \\
$\% N$ & 3.0 & 0.75 \\
$\% S$ & 0.80 & 0.05 \\
$\% O$ & 13.1 & 6.0 \\
$H / C$ & 0.02 & 0.008 \\
O/C & 0.16 & 0.06 \\
$N / C$ & 0.04 & 0.008 \\
\hline
\end{tabular}

Notes:

Except for moisture, all values in proximate analysis are presented in a dry basis $(d b)$.

$\mathrm{FC}$ values were determined by difference.

Ultimate analysis is presented in a dry and ash free basis $(d a b)$.

The values of $\% \mathrm{O}$ were estimated by difference: $\% \mathrm{O}=100 \%-(\% \mathrm{C}+\% \mathrm{H}+\% \mathrm{~N}+\% \mathrm{~S})$.

Table 3 - Amount of acidic and total basic functional groups of PSA-PA and GACN determined by Boehm's titration.

\begin{tabular}{cccccc}
\hline \multirow{2}{*}{ Material } & \multicolumn{4}{c}{ Amount of functional groups $\left(\mathbf{m m o l ~ g}^{\mathbf{- 1}}\right)$} & \multirow{2}{*}{$\mathbf{p H}_{p z c}$} \\
\cline { 2 - 5 } & Carboxylics & Lactones & Phenols & Basic (total) & \\
\hline PSA-PA & 1.29 & 0.29 & 0.96 & 0.31 & 4.3 \\
GACN & 1.03 & 0.02 & 0.31 & 0.34 & 4.8 \\
\hline
\end{tabular}


Table 4 - X-ray photoelectron spectroscopy (XPS) results for PSA-PA and GACN.

PSA-PA GACN Possible bond assignment

\begin{tabular}{|c|c|c|c|c|c|c|}
\hline & Peak & $\begin{array}{l}\text { Binding } \\
\text { Energy }(\mathrm{eV})\end{array}$ & $\%$ & $\begin{array}{l}\text { Binding } \\
\text { Energy }(e V)\end{array}$ & $\%$ & \\
\hline \multirow[t]{5}{*}{$\mathrm{C} 1 \mathrm{~s}$} & 1 & 284.5 & 58.5 & 284.6 & 68.4 & $\mathrm{C} \mathrm{sp}^{2}$; graphitic carbon \\
\hline & 2 & 285.8 & 22.0 & 285.8 & 10.2 & $\begin{array}{l}\mathrm{C}-\mathrm{C} \mathrm{sp}{ }^{3} ; \mathrm{C}-(\mathrm{O}, \mathrm{N}, \mathrm{H}) \text { : phenolic, alcoholic, } \\
\text { etheric carbon }\end{array}$ \\
\hline & 3 & 287.6 & 7.3 & 287 & 8.2 & $\mathrm{C}=\mathrm{O}$ : carbonyl or quinone \\
\hline & 4 & 289 & 6.3 & 288.9 & 5.4 & $\mathrm{O}-\mathrm{C}=\mathrm{O}$ : carboxyl or ether \\
\hline & 5 & 291 & 5.9 & 291 & 7.7 & $\pi-\pi^{*}$ transition in $\mathrm{C}$ \\
\hline \multirow[t]{5}{*}{$\mathrm{O} 1 \mathrm{~s}$} & 1 & 531.1 & 20.1 & 531.2 & 24.4 & $\mathrm{C}=\mathrm{O}$ : carbonyl or quinone \\
\hline & 2 & 533 & 54.6 & 533 & 44.4 & $\begin{array}{l}\mathrm{C}=\mathrm{O} \text { : carboxyl/carbonyl or } \\
\text { sulfoxides/sulfones; O-C: phenol/epoxy, } \\
\text { ether, ester, anhydride, carboxyl }\end{array}$ \\
\hline & 3 & - & - & 534.4 & 22.0 & $-\mathrm{COOH}$ or $-\mathrm{COOR}$ \\
\hline & & 535.3 & 17.5 & - & - & Water or chemisorbed oxygen \\
\hline & 4 & 537.6 & 7.7 & 536.5 & 9.2 & Chemisorbed water \\
\hline \multirow[t]{2}{*}{$\mathrm{N} \mathrm{1s}$} & 1 & 398.0 & 18.9 & - & - & Pyridinic N (N-6) \\
\hline & 2 & 400.1 & 81.9 & - & - & Pyrrolic N (N-5) \\
\hline
\end{tabular}

Table 5- Textural characterization of PSA-PA and GACN.

\begin{tabular}{|c|c|c|c|c|c|c|c|c|}
\hline \multirow{3}{*}{ Sample } & \multirow{3}{*}{$\begin{array}{c}\text { Apparent } \\
\text { density, } \\
\rho_{\mathrm{Hg}} \\
\left(\mathrm{g} \mathrm{cm}^{-3}\right)\end{array}$} & \multicolumn{7}{|c|}{$\mathrm{N}_{2}$ adsorption at $-196^{\circ} \mathrm{C}$} \\
\hline & & \multirow{2}{*}{$\begin{array}{c}S_{\mathrm{BET}} \\
\left(\mathbf{m}^{2} \mathbf{g}^{-1}\right)\end{array}$} & \multirow{2}{*}{$\left(\begin{array}{c}V_{\mathrm{p}} \\
\left(\mathrm{cm}^{3} \mathbf{g}^{-1}\right)\end{array}\right.$} & \multicolumn{2}{|c|}{$\begin{array}{c}\text { Dubinin-Radushkevich } \\
\text { (DR) }\end{array}$} & \multirow{2}{*}{$\underset{(\mathbf{n m})}{D}$} & \multicolumn{2}{|c|}{$\begin{array}{c}\text { Dubinin-Astakhov } \\
\text { (DA) }\end{array}$} \\
\hline & & & & $\begin{array}{c}W_{0} \\
\left(\mathrm{~cm}^{3} \mathbf{g}^{-1}\right)\end{array}$ & $\begin{array}{c}L \\
(\mathbf{n m})\end{array}$ & & $\begin{array}{c}W_{0} \\
\left(\mathrm{~cm}^{3} \mathrm{~g}^{-1}\right)\end{array}$ & $\begin{array}{c}\boldsymbol{L} \\
(\mathbf{n m})\end{array}$ \\
\hline PSA-PA & 0.61 & 671 & 0.37 & 0.27 & 1.44 & 1.11 & 0.28 & 1.58 \\
\hline GACN & 0.65 & 629 & 0.75 & 0.27 & - & 2.38 & 0.30 & 1.71 \\
\hline
\end{tabular}

$V_{\mathrm{p}}$ - total pore volume; $W_{0}$ - micropore volume; $L$ - average micropore width; $D$ - average pore diameter $\left(2 V_{\mathrm{p}} / S_{\mathrm{BET}}\right.$, assuming slit-shaped pores) 
Table 6 - Fitting results of the kinetic and equilibrium models for the adsorption of CBZ, SMX and PAR from ultra-pure water and wastewater (STP effluent) onto PSA-PA and GACN.

\begin{tabular}{|c|c|c|c|c|c|c|c|c|c|c|c|c|c|}
\hline & & \multirow{2}{*}{\multicolumn{2}{|c|}{$\begin{array}{l}\text { PSA-PA } \\
\text { CBZ }\end{array}$}} & \multicolumn{2}{|l|}{ GACN } & \multicolumn{2}{|l|}{ PSA-PA } & \multicolumn{2}{|l|}{ GACN } & \multicolumn{2}{|l|}{ PSA-PA } & \multicolumn{2}{|l|}{ GACN } \\
\hline & & & & & & SMX & & & & PAR & & & \\
\hline & & $\begin{array}{l}\text { ultra-pure } \\
\text { water }\end{array}$ & $\begin{array}{l}\begin{array}{l}\text { STP } \\
\text { effluent }\end{array} \\
\end{array}$ & $\begin{array}{l}\text { ultra-pure } \\
\text { water }\end{array}$ & $\begin{array}{l}\text { STP } \\
\text { effluent }\end{array}$ & $\begin{array}{l}\text { ultra-pure } \\
\text { water }\end{array}$ & $\begin{array}{l}\text { STP } \\
\text { effluent }\end{array}$ & $\begin{array}{l}\text { ultra-pure } \\
\text { water }\end{array}$ & $\begin{array}{l}\text { STP } \\
\text { effluent }\end{array}$ & $\begin{array}{l}\text { ultra-pure } \\
\text { water }\end{array}$ & $\begin{array}{l}\text { STP } \\
\text { effluent }\end{array}$ & $\begin{array}{l}\text { ultra-pure } \\
\text { water }\end{array}$ & STP effluent \\
\hline \multicolumn{14}{|c|}{ Kinetic models } \\
\hline \multirow[t]{3}{*}{ PFO } & $q_{t}$ & $44 \pm 1$ & $14 \pm 1$ & $52 \pm 2$ & $22 \pm 2$ & $38 \pm 3$ & $4.3 \pm 0.3$ & $60 \pm 3$ & $20 \pm 1$ & $34 \pm 3$ & $20 \pm 5$ & $23 \pm 3$ & $21.0 \pm 0.8$ \\
\hline & $k_{1}$ & $\begin{array}{l}(1.22 \pm \\
0.08) \times 10^{-3}\end{array}$ & $\begin{array}{l}(2.0 \pm 0.6) \\
\mathrm{x} 10^{-3}\end{array}$ & $\begin{array}{l}(2.3 \pm 0.2) \\
\mathrm{x} 10^{-3}\end{array}$ & $\begin{array}{l}(1.1 \pm 0.3) \\
\times 10^{-3}\end{array}$ & $\begin{array}{l}(2.4 \pm 0.6) \\
\mathrm{x} 10^{-3}\end{array}$ & $\begin{array}{l}(3.8 \pm 0.8) \\
\mathrm{x} 10^{-3}\end{array}$ & $\begin{array}{l}(1.5 \pm 0.2) \\
\times 10^{-3}\end{array}$ & $\begin{array}{l}(1.1 \pm 0.2) \\
\times 10^{-3}\end{array}$ & $\begin{array}{l}(1.1 \pm 0.3) \\
\mathrm{x} 10^{-3}\end{array}$ & $\begin{array}{l}(4 \pm 2) \\
\times 10^{-4}\end{array}$ & $\begin{array}{l}(4 \pm 1) \\
\times 10^{-3}\end{array}$ & ${ }_{3}^{(1.3 \pm 0.1) \times 10^{-}}$ \\
\hline & $\mathbf{R}^{2}$ & 0.991 & 0.863 & 0.986 & 0.932 & 0.936 & 0.944 & 0.977 & 0.971 & 0.928 & 0.923 & 0.847 & 0.986 \\
\hline \multirow[t]{3}{*}{ PSO } & $q_{t}$ & $53 \pm 2$ & $15 \pm 1$ & $63 \pm 4$ & $26 \pm 3$ & $43 \pm 5$ & $4.8 \pm 0.3$ & $71 \pm 4$ & $24 \pm 1$ & $43 \pm 7$ & $31 \pm 12$ & $26 \pm 5$ & $26 \pm 2$ \\
\hline & $k_{2}$ & $\begin{array}{l}(2.4 \pm 0.2) \\
\mathrm{x} 10^{-5}\end{array}$ & $\begin{array}{l}(2.1 \pm 0.9) \\
\mathrm{x} 10^{-4}\end{array}$ & $\begin{array}{l}(3.9 \pm 0.8) \\
\mathrm{x} 10^{-5}\end{array}$ & $\begin{array}{l}(5 \pm 2) \\
\times 10^{-5}\end{array}$ & $\frac{(7 \pm 3) \times 10^{-}}{5}$ & $\begin{array}{l}(1.1 \pm 0.3) \\
\times 10^{-3}\end{array}$ & $\begin{array}{l}(2.4 \pm 0.5) \\
\mathrm{x} 10^{-5}\end{array}$ & ${ }_{5}(5 \pm 1) \times 10^{-}$ & $\begin{array}{l}(2 \pm 1) \\
\times 10^{-5}\end{array}$ & $\begin{array}{l}(9 \pm 10) \\
\times 10^{-6}\end{array}$ & $\begin{array}{l}(2 \pm 1) \\
x 10^{-4}\end{array}$ & $\begin{array}{l}(5 \pm 2) \\
x 10^{-5}\end{array}$ \\
\hline & $\mathbf{R}^{2}$ & 0.995 & 0.916 & 0.980 & 0.950 & 0.901 & 0.952 & 0.983 & 0.986 & 0.913 & 0.918 & 0.790 & 0.972 \\
\hline \multicolumn{14}{|c|}{ Isotherm models } \\
\hline \multirow[t]{3}{*}{ Langmuir } & $q_{m}$ & $24 \pm 5$ & $10 \pm 1$ & $85 \pm 14$ & $\begin{array}{l}\text { Not } \\
\text { Converged }\end{array}$ & $44 \pm 5$ & $6 \pm 1$ & $98 \pm 17$ & $49 \pm 6$ & $31 \pm 6$ & $34 \pm 9$ & $64 \pm 12$ & $106 \pm 40$ \\
\hline & $K_{L}$ & $1.3 \pm 0.8$ & $0.5 \pm 0.1$ & $2.2 \pm 0.9$ & & $0.6 \pm 0.2$ & $1 \pm 1$ & $0.6 \pm 0.2$ & $0.30 \pm 0.06$ & $0.6 \pm 0.2$ & $0.3 \pm 0.1$ & $0.6 \pm 0.2$ & $0.2 \pm 0.1$ \\
\hline & $\mathbf{R}^{2}$ & 0.895 & 0.984 & 0.946 & & 0.970 & 0.866 & 0.967 & 0.995 & 0.973 & 0.967 & 0.960 & 0.982 \\
\hline \multirow[t]{3}{*}{ Freundlich } & $\boldsymbol{K}_{F}$ & $12 \pm 2$ & $3.2 \pm 0.2$ & $57 \pm 3$ & $12 \pm 1$ & $16 \pm 1$ & $3.2 \pm 0.5$ & $36 \pm 3$ & $10.6 \pm 0.4$ & $12 \pm 1$ & $8 \pm 1$ & $23 \pm 3$ & $19 \pm 1$ \\
\hline & $n$ & $3 \pm 1$ & $1.8 \pm 0.2$ & $2.4 \pm 0.4$ & $1.1 \pm 0.1$ & $1.9 \pm 0.2$ & $3 \pm 1$ & $1.6 \pm 0.3$ & $1.3 \pm 0.1$ & $1.7 \pm 0.3$ & $1.4 \pm 0.2$ & $2.0 \pm 0.5$ & $1.2 \pm 0.1$ \\
\hline & $\mathbf{R}^{2}$ & 0.845 & 0.969 & 0.966 & 0.950 & 0.968 & 0.781 & 0.937 & 0.986 & 0.958 & 0.947 & 0.923 & 0.984 \\
\hline \multirow[t]{4}{*}{ Sips } & $q_{m}$ & $20 \pm 4$ & $8 \pm 1$ & $\begin{array}{l}\text { Ambiguous } \\
\text { fitting }\end{array}$ & $\begin{array}{l}\text { Ambiguous } \\
\text { fitting }\end{array}$ & $58 \pm 45$ & $5.0 \pm 0.3$ & $70 \pm 10$ & $\begin{array}{l}\text { Ambiguous } \\
\text { fitting }\end{array}$ & $18.5 \pm 0.6$ & $19 \pm 2$ & $43 \pm 2$ & $\begin{array}{l}\text { Ambiguous } \\
\text { fitting }\end{array}$ \\
\hline & $\boldsymbol{K}_{S}$ & $2 \pm 2$ & $0.7 \pm 0.2$ & & & $0.4 \pm 0.4$ & $5 \pm 4$ & $1.3 \pm 0.5$ & & $2.4 \pm 0.4$ & $0.8 \pm 0.2$ & $1.3 \pm 0.2$ & \\
\hline & $N$ & $0.6 \pm 0.4$ & $0.8 \pm 0.2$ & & & $1.2 \pm 0.6$ & $0.3 \pm 0.1$ & $0.6 \pm 0.1$ & & $0.39 \pm 0.04$ & $0.5 \pm 0.1$ & $0.43 \pm 0.06$ & \\
\hline & $\mathbf{R}^{2}$ & 0.905 & 0.986 & & & 0.971 & 0.959 & 0.979 & & 0.998 & 0.982 & 0.996 & \\
\hline
\end{tabular}

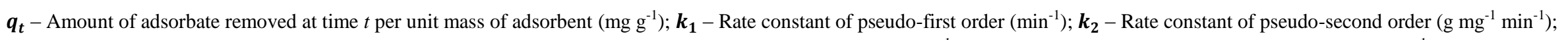

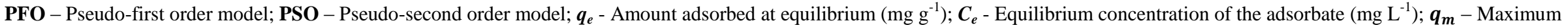

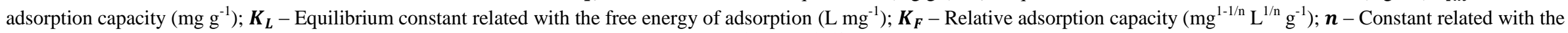
degree of non-linearity of the equation; $\boldsymbol{K}_{\boldsymbol{S}}$ - Affinity coefficient of the Sips model $\left(\mathrm{mg} \mathrm{g}^{1-}\left(\mathrm{mg} \mathrm{L}^{-1}\right)^{-1 / \mathrm{N}}\right) ; \boldsymbol{N}-$ degree of non-linearity of the Sips model. 


\section{Figure Captions}

Figure 1 - Pore size distribution of PSA-PA and GACN.

Figure 2 - Scanning electron microscopy (SEM) images for PSA-PA and GACN at magnifications of 300x, 3000x, $10000 x$ and $50000 x$.

Figure 3 - Kinetic experimental results and fittings to pseudo-first order (PFO, full line) and pseudo-second order (PSO, dashed line) kinetic models for the adsorption of CBZ, SMX and PAR onto PSA-PA (dots) and GACN (triangles) in ultra-pure water (full symbols) and in wastewater (open symbols). Note: Error bars stand for standard deviations $(\mathrm{N}=3)$.

Figure 4 - Equilibrium experimental data and fittings to Langmuir (full line) and Freundlich (dashed line) isotherm models for the adsorption of CBZ, SMX and PAR onto PSA-PA (dots) and GACN (triangles) in ultra-pure water (full symbols) and in wastewater (open symbols). Note: Error bars stand for standard deviations $(\mathrm{N}=3)$. 


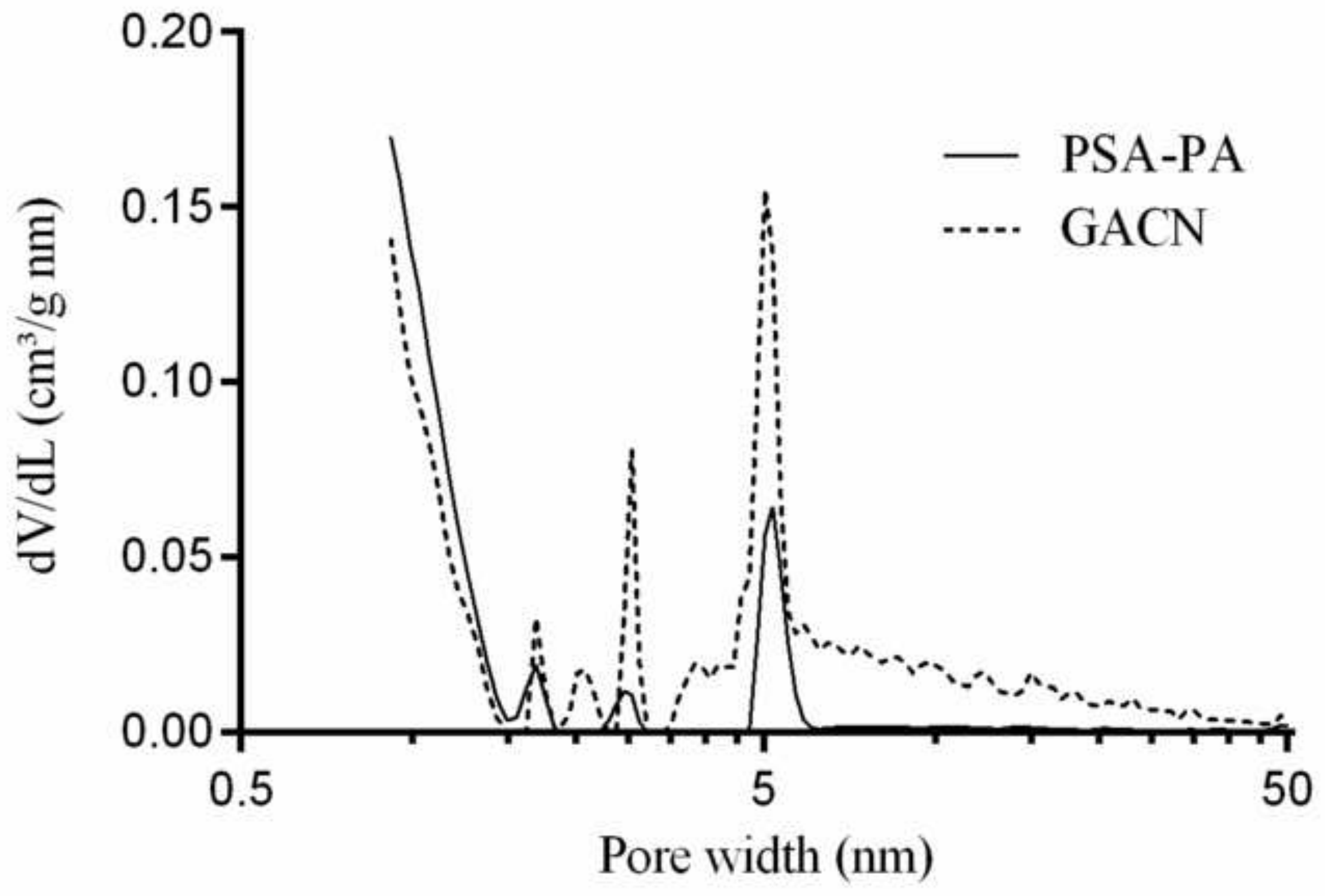


Click here to download high resolution image
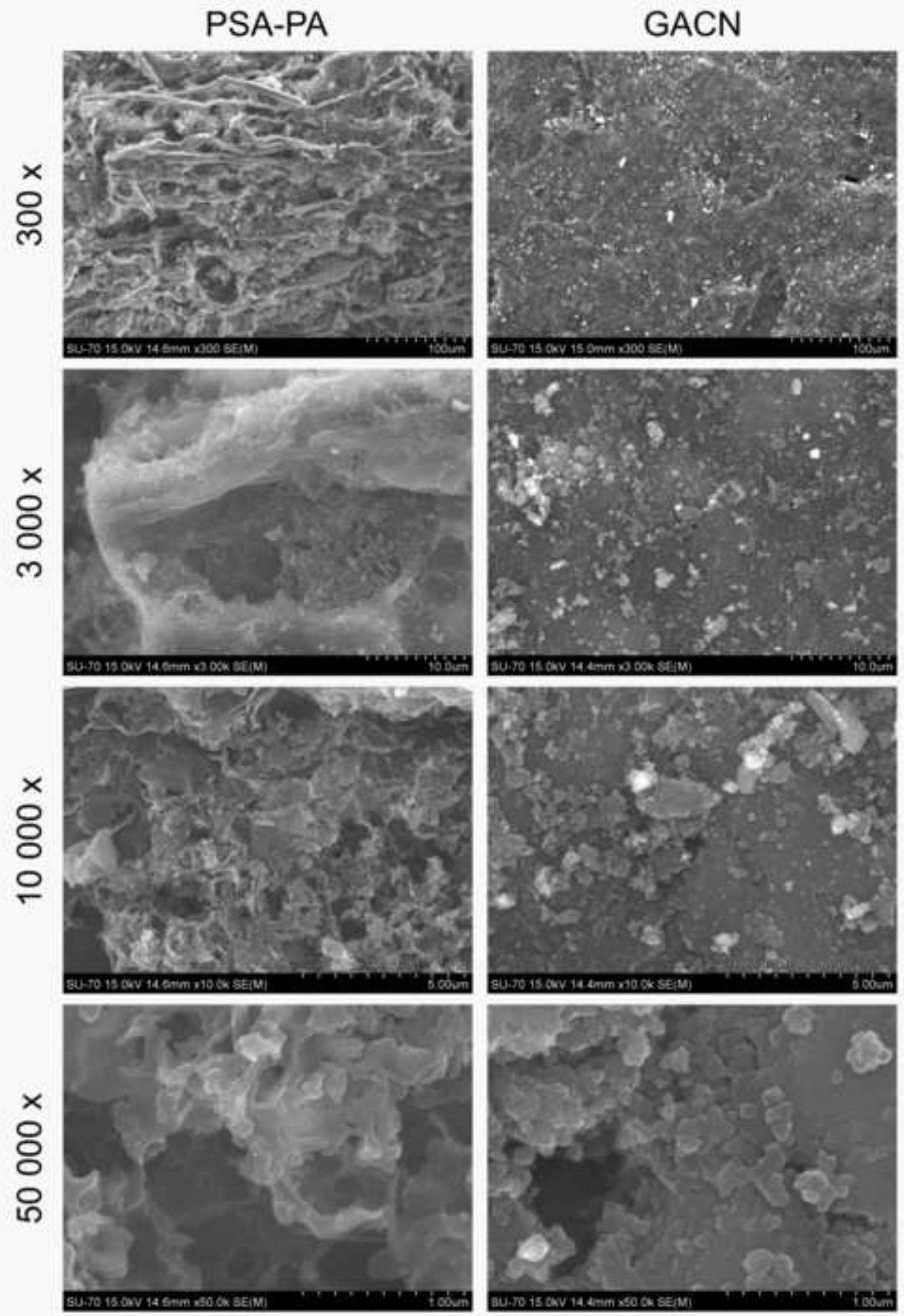
Click here to download high resolution image
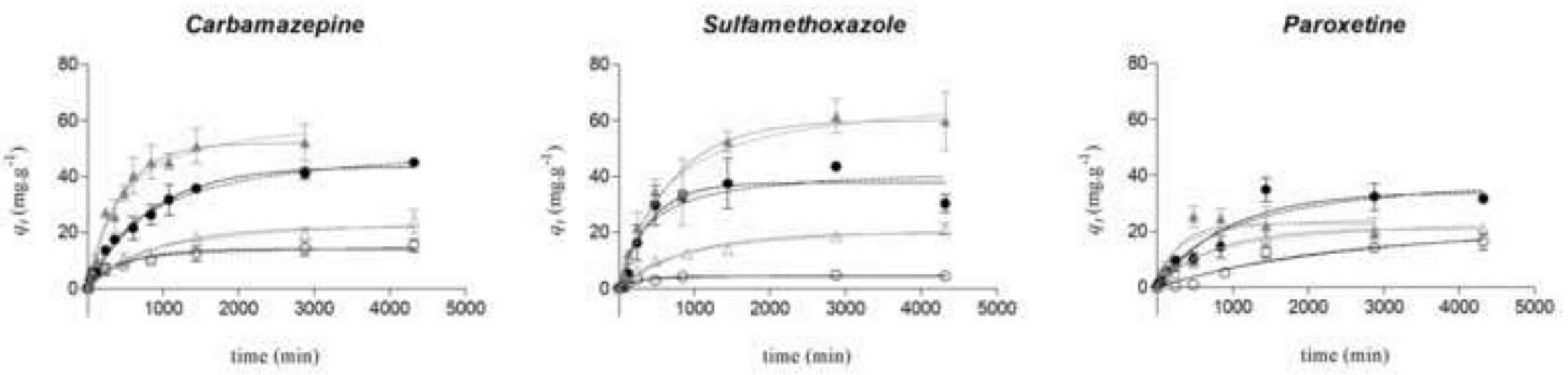
Click here to download high resolution image
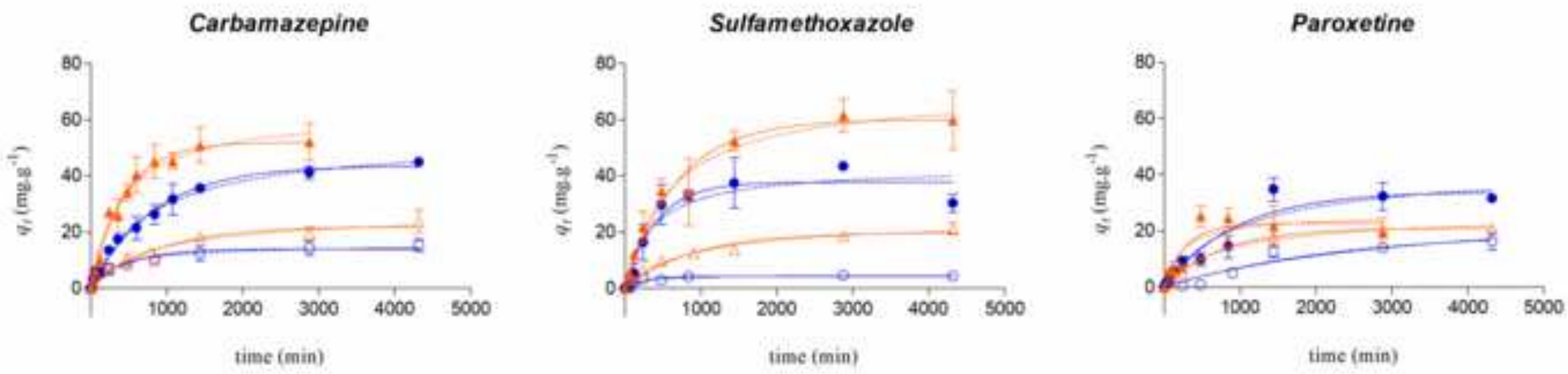
Click here to download high resolution image
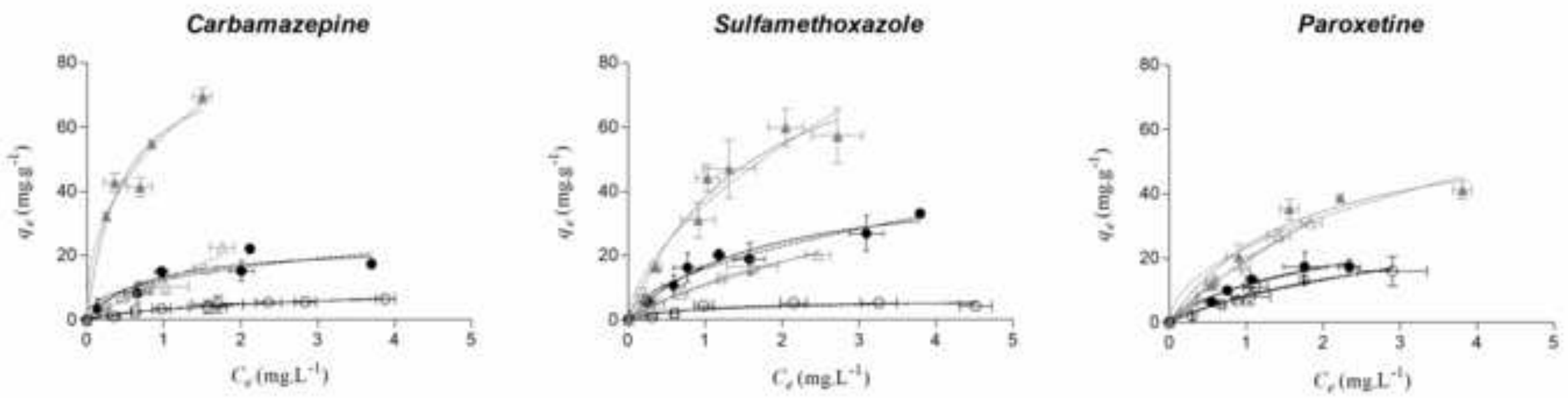
Click here to download high resolution image
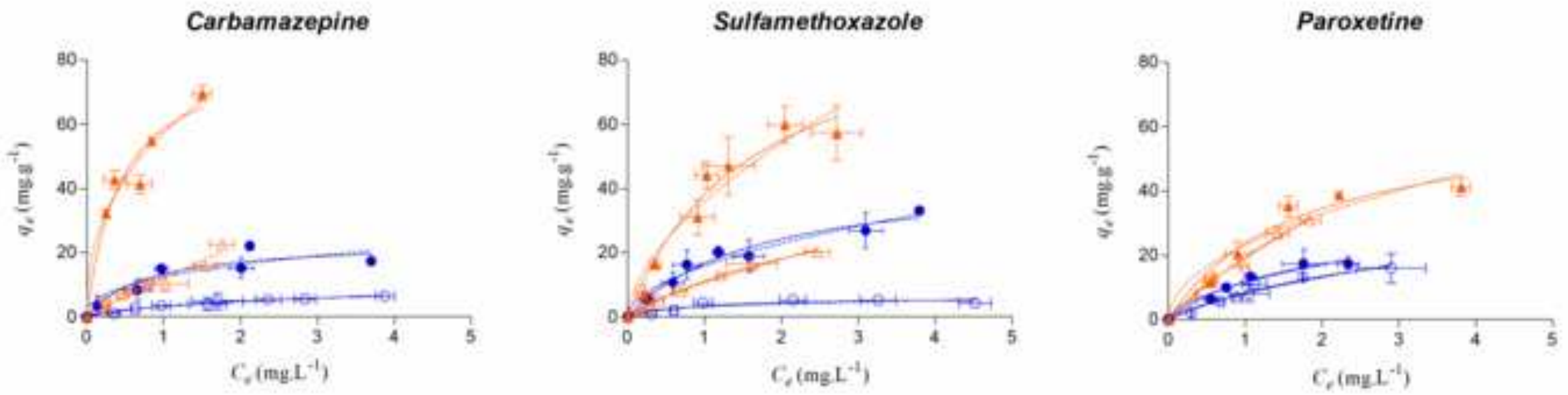

Supplementary material for on-line publication only Click here to download Supplementary material for on-line publication only: supplementary material_REVISED.pdf

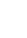
Click here to download Supplementary material tor on-ine publicatic 